\title{
Methodological and Ethical Quality Checklist Assessment in Issues of Annals of Family Medicine Clinical Trials (2010-2013)
}

\author{
Castano Garcia', Guillen Grima ${ }^{2,3}$ and Leon Sanz ${ }^{4}$
}

${ }^{1}$ Corella Health Center, Navarra Health Service, Corella, Navarra, Spain

2 Preventive Medicine, University of Navarra Clinic, Pamplona, Navarra, Spain

${ }^{3}$ IDISNA (Instituto de Investigacion Sanitaria de Navarra/Navarra Health Research Institute),Pamplona, Navarra, Spain

${ }^{4}$ School of Medicine, University of Navarra, Pamplona, Navarra, Spain

\begin{abstract}
Introduction: At present, the quality of the publication of Control Trials (CTs) in medical journals improved due to the inclusion of the CONSORT (CONsolidated Standards of Reporting Trials) standards and the Declaration of Helsinki. The aim is to analyse methodological and ethical quality of published CTs in Annals of Family Medicine journal.

Material and methods: We use a 133-item checklist divided into 11 sections based on CONSORT and the Declaration of Helsinki. The Confidence Interval of $95 \%(95 \% \mathrm{Cl})$ of Clopper-Pearson for $\mathrm{K}$ average is calculated.

Results: We found 35 CTs in a literature review (2010-2013) on March 25, 2014 according to PRISMA (Preferred Reporting Items for Systematic reviews and Meta-Analysis). CT was mentioned in all heading/subheadings; CT controlled parallels in $80 \%$; cluster type $45.7 \%$. The most observed method was masked, active-controlled, decentralized randomization. The most frequently found category was an open CT assessing a medical intervention, with a positive significant result surveyed. The most common Informed Consent (IC) was in writing, not clearly voluntary, without prior knowledge and doubtful. It was not withdrawn in $45.7 \%$ of cases. A grant/scholarship was found to be the most frequent incentive for researchers. In $28 \mathrm{CTs}$ there was no conflict of interest. The $\mathrm{k}$ average was $0.93(95 \% \mathrm{Cl}, 0.90-0.96)$.
\end{abstract}

Conclusions: CT published "standard" characteristic are indicated. Following the CONSORT standards publication, it has increased the overall quality of the CTs published. But there are some areas for improvement in the methodological and ethical quality of the CTs published from 2010 to 2013 in Annals of Family Medicine.

Keywords: Checklist; Clinical trials; Family practice; Methodological and ethical quality; Correlation coefficient

\section{Introduction}

In the present investigation the Randomized Clinical Trial (RCT) is the "gold standard" for evaluating new therapies or strategies in medicine [1]. A low quality in RCTs design or publication, it could lead to an underestimation of the risk or even false, using treatments that may be less or even harmful, and could produce daily clinical practice consequences [2]. So a higher quality in published clinical trials to help choose the best therapies for patients.

There are different methods of assessing the ethical quality of Clinical Trials (CTs) publications, amongst which Dechartres et al. identified 26 scales or checklists based on CONSORT (Consolidated Standards of Reporting Trials) [3]. In this way they obtained increased data on methodological issues, but only $29 \%$ adequate masked allocation. They also found that quality evaluation still presents significant problems [4]. Katrak et al. also observed heterogeneity in the use of criteria and unclear definition in the scales, which might limit the relevance of the results [5].

No studies have been found assessing the methodological and ethical quality of the CTs published in Annals of Family Medicine journal.

The aim is to analyze quantitative and qualitative methodological and ethical quality of published clinical trials in Annals of Family Medicine journal, between 2010-2013. We chose this journal because it has the highest impact factor in Family Medicine (4.613), published CTs, CONSORT endorsement and has an important general quality. We want to know how clinical trials are performing in primary care, as this will help to improve the design and publication of these.

\section{Materials and Methods}

On March 25, 2014 we use a hand search and subsequent checklist to analyze CTs published in Annals of Family Medicine since January 1, 2010 to December 31, 2013.

It is a print edition with free online access (no "open access"), which follows the CONSORT standards [6,7] and the ICMJE (International Committee of Medical Journal Editors) recommendations [8].

We follow the CONSORT statement [3] and PRISMA (Preferred Reporting Items for Systematic reviews and Meta-Analyses) [9], which provide higher quality checklists [8] for CTs publishing [10,11], and have been implemented in over 400 journals and editorial groups as ICMJE [3]. We will also use the most recent edition of the Declaration of Helsinki (2013) [12,13].

\section{Inclusion and exclusion criteria}

We obtained published studies from CONSORT [14] to increase the quality [15]. We included all CTs carried out in humans. Exclusion criteria were: 1) CT assessing diagnostic test or costs; 2) "Letters to the editor" type studies and pilot tests; 3 ) Continuation CT (as full

${ }^{*}$ Corresponding author: Alberto Castano-Garcia, $\mathrm{M}^{\mathrm{a}}$ Teresa Saenz de Heredia, $\mathrm{n}^{\circ}$ 33. Corella (31591 (Navarra), Spain, Tel: 651030 149; E-mail: albertodoc@gmail.com

Received January 11, 2016; Accepted February 18, 2016; Published February 29, 2016

Citation: Garcia C, Grima G, Sanz L (2016) Methodological and Ethical Quality Checklist Assessment in Issues of Annals of Family Medicine Clinical Trials (2010 2013). Fam Med Med Sci Res 5: 200. doi:10.4172/2327-4972.1000200

Copyright: $\odot 2016$ Garcia C, et al. This is an open-access article distributed under the terms of the Creative Commons Attribution License, which permits unrestricted use, distribution, and reproduction in any medium, provided the original author and source are credited. 
publications or "short reports") for the study of secondary variables or secondary analysis of a previously published CT with the same number of subjects.

\section{Checklist to assess the ethical and methodological quality}

We reviewed a checklist [16] based on CONSORT [17] that had 80 items divided into 8 sections. We have updated to a 133 -item checklist in eleven sections. It was applied to assess their ethical and methodological quality. Following the Declaration of Helsinki [18], items were modified or created to adapt them to Primary Care (PC) with the assistance of the PRECIS (Pragmatic-Explanatory Continuum Indicator Summary) tool [19]. More explicit variables were created for placebo use. We introduced AHRQ [20] ("Agency for Healthcare Research and Quality") criteria and the Jadad quality scale. We use the assessment by a DSMB (Data and Safety Monitoring Board) and "stopping rules" (Haybittle-Peto, Pocock, O’Brien-Fleming) [21]. We also evaluated sequential trials, optimized evaluated by the CREC (Clinical Research Ethics Committee) or futility analysis. We stressed race and language, incentives, training in Bioethics, types of conflicts of interest and sponsor influence.

\section{Analysis and data extraction}

Two tables with frequency and rates for qualitative variables were made. We built a table with the mean, median, mode, minimum, maximum and statistical percentiles (P25, P50, P75) for quantitative variables. Data were calculated using SPSS 20.0.

Comparable variables on the $\kappa, \kappa$ means and $95 \% \mathrm{CI}$ value was obtained [22].

This article does not contain any studies with human participants or animals performed by any of the authors.

Informed consent was no necessary to obtain because no individual participants were included in the study.

\section{Results}

We found 35 CTs that met the inclusion criteria (Figure 1). Most were observational studies. Afterwards we eliminated three of these (not meet the inclusion criteria) and final analysis was performed.

Table 1 shows the frequencies and rates for the most representative items.

\section{Assessment of methodological quality}

In the section on "justification and objectives" of our checklist, we observed that the following appear in all: 1) CT in heading or subheading, 2) related CTs, 3) systematic review cited and 4) a priori hypothesis.

Regarding the "clinical trial type", $68.6 \%$ were performed in $>5$ centers and $14.3 \%$ in $\leq 5$. In $80 \%$ some authors are epidemiologists or statisticians.

In the 3rd section, the "clinical trial design" is evaluated. In $80 \%$, there were controlled parallel-groups and controlled factorials in 4 CTs. There is a tendency to be more pragmatic than explanatory according to the criteria of AHRQ.

Baseline comparison was made in a table following CONSORT [14] for almost all CTs (34), and "p" in $68.6 \%$. Only the CT by Licciardone et al. [23] is sequential; moreover it uses the O'Brien Fleming stopping rule. The effectiveness of masking and withdrawals due to adverse events were found in only 5 CTs and the latter were uncertain in 6 studies (Table 2)
The "choice of subjects" is the next section (4th). The subjects are White in $54.3 \%$, $45.7 \%$ African Americans, $37.1 \%$ Hispanic and in 8 studies Asian. Race is not indicated in $42.9 \%$, not specified in 13 CTs, and in 4, subjects are ethnic minorities such as American Indian and Vietnamese. The inclusion of immigrant or low-income groups has increased in the last three years: 2011 (1), 2012 and 2013 (3). We have not observed the inclusion of "vulnerable" people [24].

In the $5^{\text {th }}$ section the "sample size" is evaluated. Quantitative variables are reported in a table (Table 3). The "alpha" error is $74.3 \%$, "beta" is $82.9 \%$, the magnitude of the minimum difference to be found is $80 \%$, and the "flowchart" is $85.7 \%$.

Regarding the "Description of treatment" (section 6), with an effective standard treatment, placebo or non-intervention has not been used as a control in $62.9 \%$. A strong and compelling case for the use of placebo or non-intervention for methodological reasons was given in 6 CTs, and the determination of efficacy and safety in two. In $37.1 \%$, there were serious adverse events in general (including death), and it was unclear in 3 studies. The "intention to treat analysis" was conducted in 15 CTs, "not indicated" (to be performed but not mentioned) in 3, and was "unclear" (to be mentioned but not performed properly) in one. According to the Jadad score, 15 studies were of good quality (3), 16 low-grade (1 or 2) and 4 excellent (5).

The 7th section deals with the "development of the trial and assessment the answer". The "primary outcome variable" or "endpoint" is not described in one CT and is "unclear" in $11.4 \%$. "Multivariate analysis" is applied in $42.9 \%$. There is a DSMB in $14.3 \%$. Finally, CONSORT standards mentioned that it followed in $28.6 \%$.

\section{Assessment of other ethical quality parameters}

In the 8th section, the most important variables are represented in Table 2. Two CTs included minors as research subjects. Parents or representative completed Informed Consent (IC) in one of them and the other this completion was "unclear".

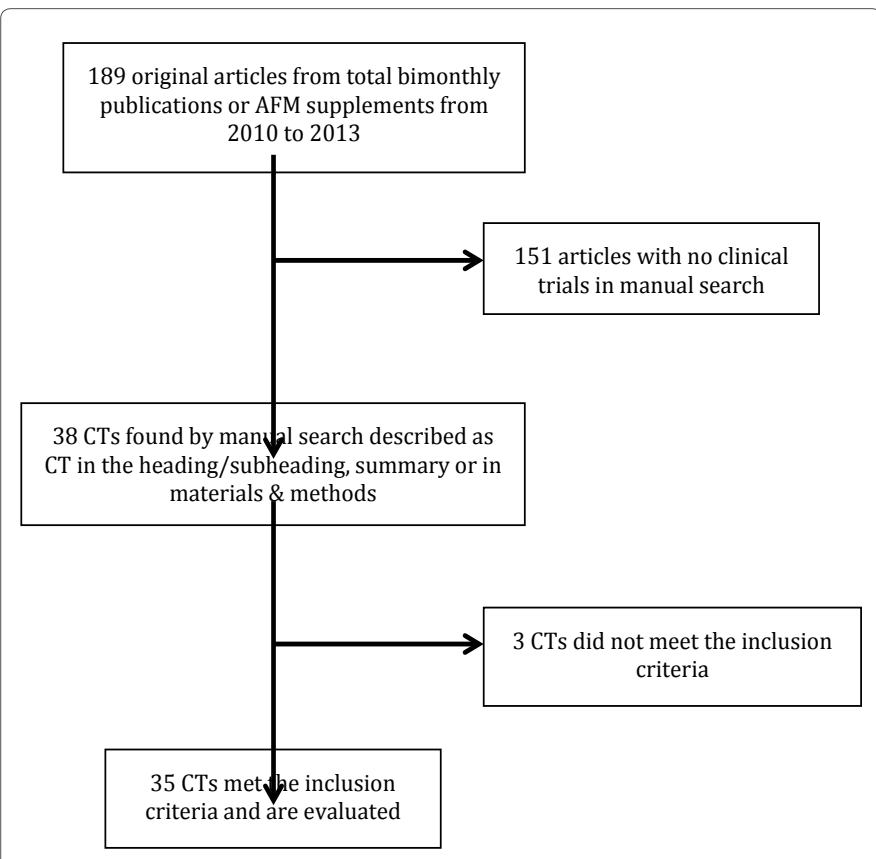

Figure 1: Flow diagram with the choice of studies for analysis according to PRISMA [10]. 
Citation: Garcia C, Grima G, Sanz L (2016) Methodological and Ethical Quality Checklist Assessment in Issues of Annals of Family Medicine Clinical Trials (2010-2013). Fam Med Med Sci Res 5: 200. doi:10.4172/2327-4972.1000200

Page 3 of 7

\begin{tabular}{|c|c|c|c|}
\hline VARIABLE & VALUE & FREQ & $\%$ \\
\hline \multirow[t]{5}{*}{ Author nationality } & USA & 24 & 68.6 \\
\hline & United Kingdom & 1 & 2.9 \\
\hline & Scandinavia & 1 & 2.9 \\
\hline & Other European & 5 & 14.3 \\
\hline & Other & 4 & 11.4 \\
\hline \multirow[t]{4}{*}{$\begin{array}{l}\text { Country where the study was } \\
\text { performed }\end{array}$} & North America & 24 & 68.6 \\
\hline & Australia & 1 & 2.9 \\
\hline & Europe & 7 & 20.0 \\
\hline & Other & 3 & 8.6 \\
\hline \multirow[t]{4}{*}{ Type of funding } & Nonprofit: public & 24 & 68.6 \\
\hline & Nonprofit: private & 14 & $40.0^{*}$ \\
\hline & Pharmaceuticals industry & 3 & $8.6^{*}$ \\
\hline & Not indicated & 3 & 8.6 \\
\hline \multirow[t]{5}{*}{ Random allocation system } & Simple randomization & 12 & $34.3^{*}$ \\
\hline & Blocked & 11 & $31.4^{*}$ \\
\hline & Stratified & 4 & $11.5^{*}$ \\
\hline & Cluster & 16 & 45.7 \\
\hline & Minimization & 1 & 2.9 \\
\hline \multirow[t]{3}{*}{$\begin{array}{l}\text { Was a masked method of } \\
\text { randomization followed? }\end{array}$} & Yes & 24 & 68.6 \\
\hline & No & 7 & 20.0 \\
\hline & Unclear & 4 & 11.4 \\
\hline \multirow[t]{5}{*}{$\begin{array}{l}\text { Was the method of masked } \\
\text { randomization used specified? }\end{array}$} & Decentralized & 16 & 45.7 \\
\hline & $\begin{array}{l}\text { Opaque envelopes } \\
\text { opened sequentially }\end{array}$ & 6 & $17.1^{*}$ \\
\hline & Other & 5 & 14.3 \\
\hline & Not mentioned & 5 & 14.3 \\
\hline & $\begin{array}{l}\text { No masked } \\
\text { randomization }\end{array}$ & 7 & 20.0 \\
\hline \multirow[t]{4}{*}{ Type of control } & Placebo & 4 & 11.4 \\
\hline & Active treatment & 25 & $71.5^{*}$ \\
\hline & No treatment & 7 & $20.0^{*}$ \\
\hline & Other & 1 & 2.9 \\
\hline \multirow[t]{5}{*}{$\begin{array}{l}\text { Is the degree of masking } \\
\text { assessment indicated? }\end{array}$} & Open or Not blind & 16 & 45.7 \\
\hline & Single blind & 5 & 14.3 \\
\hline & Double-blind & 2 & 5.7 \\
\hline & $\begin{array}{c}\text { Blind assessment by } \\
\text { others }\end{array}$ & 8 & 22.9 \\
\hline & Triple-blind & 4 & 11.4 \\
\hline \multirow[t]{4}{*}{$\begin{array}{l}\text { Does it explain why the trial is } \\
\text { not blind? }\end{array}$} & Yes & 1 & 2.9 \\
\hline & No & 13 & 37.1 \\
\hline & Unclear & 2 & 7.7 \\
\hline & Blind CT & 19 & 54.3 \\
\hline \multirow[t]{4}{*}{ Is masking method indicated? } & Yes & 12 & 34.3 \\
\hline & No & 5 & 14.3 \\
\hline & Unclear & 2 & 5.7 \\
\hline & Open CT & 16 & 45.7 \\
\hline \multirow[t]{4}{*}{ Treatment Type } & Drug already marketed & 3 & 8.6 \\
\hline & Medical device & 4 & 11.4 \\
\hline & $\begin{array}{l}\text { Medical procedure } \\
\text { method }\end{array}$ & 26 & $74.3^{*}$ \\
\hline & Other $^{a}$ & 8 & $22.9^{*}$ \\
\hline \multirow[t]{5}{*}{ Trial outcome } & $\begin{array}{l}\text { Therapy significantly } \\
\text { improved }\end{array}$ & 16 & 45.7 \\
\hline & No difference & 12 & 34.3 \\
\hline & $\begin{array}{l}\text { Difference according to } \\
\text { author but not significant }\end{array}$ & 3 & 8.6 \\
\hline & Other $^{b}$ & 1 & 2.9 \\
\hline & Trend toward treatment & 3 & 8.6 \\
\hline
\end{tabular}

\begin{tabular}{|c|c|c|c|}
\hline $\begin{array}{c}\text { Assessment of outcome } \\
\text { ("endpoint") }\end{array}$ & Death & 1 & 2.9 \\
\hline & Laboratory diagnosis & 9 & 25.7 \\
\hline & Symptomatic diagnosis & 2 & 5.7 \\
\hline & $\begin{array}{c}\text { Blood pressure } \\
\text { manometer }\end{array}$ & 9 & $25.7^{*}$ \\
\hline & Survey & 21 & $60.0^{*}$ \\
\hline & Measuring range & 5 & $14.3^{*}$ \\
\hline
\end{tabular}

Sum of several similar variables. Proportions add up to more than $100 \%$ because of multiresponse

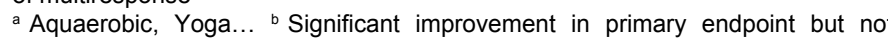
remainder

Table 1: Methodological variables: frequencies and rates.

\begin{tabular}{|c|c|c|c|}
\hline VARIABLE & VALUE & FREQ & $\%$ \\
\hline \multirow[t]{2}{*}{$\begin{array}{l}\text { Does it mention whether } \\
\text { informed consent was obtained? }\end{array}$} & Yes & 23 & 65.7 \\
\hline & No & 12 & 34.3 \\
\hline \multirow[t]{3}{*}{$\begin{array}{l}\text { Was the informed consent } \\
\text { obtained voluntarily? }\end{array}$} & Yes & 6 & 17.1 \\
\hline & Unclear & 18 & 51.4 \\
\hline & No informed consent & 11 & 31.4 \\
\hline \multirow{4}{*}{$\begin{array}{l}\text { Is the type of consent is } \\
\text { specific, and is it witnessed and } \\
\text { documented? }\end{array}$} & Oral (no mention of witness) & 1 & 2.9 \\
\hline & Written & 11 & 31.4 \\
\hline & $\begin{array}{l}\text { Not mentioned (whether } \\
\text { written/oral) }\end{array}$ & 11 & 31.4 \\
\hline & No informed consent & 12 & 34.3 \\
\hline \multirow[t]{3}{*}{$\begin{array}{l}\text { Does patient receive information } \\
\text { to obtain informed consent? }\end{array}$} & Yes & 5 & 14.3 \\
\hline & No & 19 & 54.3 \\
\hline & No informed consent & 11 & 31.4 \\
\hline \multirow[t]{4}{*}{$\begin{array}{l}\text { Is informed consent dependent } \\
\text { or under pressure? }\end{array}$} & Dependence relationship & 10 & 28.6 \\
\hline & No & 2 & 5.7 \\
\hline & Unclear & 11 & 31.4 \\
\hline & No informed consent & 12 & 34.3 \\
\hline \multirow[t]{4}{*}{$\begin{array}{l}\text { Is a qualified unrelated person } \\
\text { designated to obtain the IC? }\end{array}$} & Yes & 1 & 2.9 \\
\hline & No & 6 & 17.1 \\
\hline & Unclear & 14 & 40.0 \\
\hline & No informed consent & 14 & 40.0 \\
\hline \multirow{4}{*}{$\begin{array}{l}\text { Is the IC of the subject } \\
\text { participant withdrawn during } \\
\text { the CT? }\end{array}$} & Yes & 2 & 5.7 \\
\hline & No & 16 & 45.7 \\
\hline & Unclear & 6 & 17.1 \\
\hline & No informed consent & 11 & 31.4 \\
\hline \multirow{6}{*}{$\begin{array}{l}\text { Are researchers, participating } \\
\text { institutions and/or subjects } \\
\text { incentivized? }\end{array}$} & No & 16 & 45.7 \\
\hline & To researchers & 15 & 42.9 \\
\hline & To participating institutions & 3 & 8.6 \\
\hline & To subject involved & 3 & $8.6^{*}$ \\
\hline & To research assistants & 2 & 5.7 \\
\hline & $\begin{array}{l}\text { To physician cluster } \\
\text { involved }\end{array}$ & 3 & $8.6^{*}$ \\
\hline \multirow[t]{5}{*}{$\begin{array}{l}\text { If so, specify the type and } \\
\text { amount }\end{array}$} & Bonus to researchers & 7 & 20.0 \\
\hline & $\begin{array}{l}\text { Grant or fellowship for } \\
\text { researchers }\end{array}$ & 12 & $34.3^{*}$ \\
\hline & $\begin{array}{l}\text { Bonus to participating } \\
\text { centers }\end{array}$ & 3 & 8.6 \\
\hline & Bonus to subject involved & 3 & $8.6^{*}$ \\
\hline & No incentives given & 16 & 45.7 \\
\hline
\end{tabular}




\begin{tabular}{|c|c|c|c|}
\hline & Bonus to research assistant & 3 & 8.6 \\
\hline & $\begin{array}{c}\text { Bonus to physician cluster } \\
\text { involved }\end{array}$ & 2 & 5.7 \\
\hline $\begin{array}{c}\text { Has the incentive offered been } \\
\text { provided? }\end{array}$ & Yes & 17 & 48.6 \\
\hline & No & 2 & 5.7 \\
\hline $\begin{array}{c}\text { Information provided in relation } \\
\text { to conflict of interest }\end{array}$ & No conflict of interest & 28 & 80.0 \\
\hline & Payment or company grant & 6 & 17.1 \\
\hline & $\begin{array}{c}\text { An author works for } \\
\text { company }\end{array}$ & 3 & $8.6^{*}$ \\
\hline & An author has shares in the \\
company & 1 & 2.9 \\
\hline & Other a & 1 & 2.9 \\
\hline
\end{tabular}

*Sum of several similar variables. Proportions add up to more than $100 \%$ because of multiresponse

${ }^{\text {a }}$ An author had worked as consultant for the company provided an electronic too to help make medical decisions.

Table 2: Ethical variables: frequencies and rates.

The confidentiality of the participants' personal information was found in only $17.1 \%$. In $8.6 \%$ of the CTs, people were injured by their participation, but none were compensated. In $22.9 \%$ a study protocol is not stated.

In all CTs possible conflicts of interest were stated. The influence by the sponsor was not described in $48.6 \%$. The studies reviewed are registered in $57.1 \%$ of the cases.

\section{Calculation of Kappa index}

The authors (FGG and ACG) independently reviewed the 35 articles chosen following the checklist. For the completion of the variables they followed detailed instructions and discrepancies were resolved by consensus. In 82 variables we found a $\kappa$ average of 0.93 (95\% CI, 0.90-0.96), optimal) [25]. In Table 4 the variables assessed by $\kappa$ appear.

\section{Discussion}

In current Family Medicine RCT is one of the main tools to compare a new treatment with other standard or a placebo. Therefore the quality of the publication of new RCTs, is crucial for a reliable picture of the results they can obtain in order to implement them safely on clinical practice.
Clinical trials published in "Annals of Family Medicine" journal are most frequently named in Family Medicine. Therefore, our study evaluates the quality of these, for a fairly good idea of how they are developing RCTs in Family Medicine. We assess one journal only to have a minimal publication bias.

We observed a higher general quality if we compare our study with similar. In a related study [16] there is a progressive increase in masked randomization: $33.1 \%$ (1993-95), 56.7\% (2004) and 68.6\% in 2010-13. It could be explained because after CONSORT, it was stressed that it was essential to reduce selection bias. In contrast, double blind trial is less frequent (5.7\%) versus earlier revisions (43.9\% (1993-1995) and 43.3\% (2004) and placebo use as a control element has also decreased: $37.0 \%$ (93-95), $16.7 \%$ (2004) and $11.4 \%$ (2010-13). Probably due to the treatments used less frequent damaging. The figures for "intentionto-treat" and "multivariate" analysis remain stable ( $47.7 \%$ and $44.2 \%$, $42.9 \%$ (both), although both were higher in 2004 (70\% each). This may be due to the increased statistical power searched in recent years.

Regarding the indicators of ethical quality [16], the number of CTs without a reference to CREC has dropped, particularly in the latest period (25.5\% (93-95), 20\% (2004) and 5.7\% (2010-13). This is perhaps attributable to CONSORT standards. Coinciding with Ndebele et al. [12], CTs on children or disabled persons have been very infrequent in the three studies. A possible explanation could be that in Family Medicine children as research subjects are uncommon.

In Sinha et al. [26], a Jadad score $\geq 3$ was found in $40 \%$, which is slightly higher than the rate found in our study (54.3\%). This is perhaps because there are less RCT.

We agree with Agha et al. [27] that the country where most CTs were carried out was the US (15). Possibly because it is the country where more research is conducted.

In contrast with our results, O'Meara et al. [28], in their review observed very limited information on the sample size and masking. We think it could be because most studies reviewed are low quality.

We agree with Laframboise et al. [29] when they describe all the justification and objectives. This description is possibly necessary to assess the CTs results.

Panic et al. [30] grant and sponsors were described in 70\%, which is more frequent than in our findings. This could be because "Annals

\begin{tabular}{|c|c|c|c|c|c|c|c|c|}
\hline VARIABLE & MEAN & MEDIAN & MODE & MINIMUM & MAXIMUM & $\mathrm{P} 25$ & P50 & P75 \\
\hline Subjects evaluated & 6403 & 1102 & 88 (several) & 88 & 77000 & 372 & 1102 & 3930 \\
\hline Subjects evaluated (cluster) & 78 & 48 & 40 & 25 & 373 & 38 & 48 & 77 \\
\hline Subjects refuse to participate & 1080 & 49 & 0 & 0 & 18882 & 0 & 49 & 245 \\
\hline Subjects refuse to participate (cluster) & 3 & 0 & 0 & 0 & 15 & 0 & 0 & 8 \\
\hline Subjects randomized & 1744 & 417 & 237 & 84 & 21762 & 231 & 417 & 1826 \\
\hline Subjects randomized (cluster) & 66 & 40 & 27 (several) & 19 & 373 & 27 & 40 & 56 \\
\hline Subjects were assigned treatment & 1709 & 388 & 237 & 84 & 21762 & 231 & 388 & 1771 \\
\hline Subjects were assigned treatment (cluster) & 64 & 40 & 41 & 19 & 373 & 27 & 40 & 54 \\
\hline Subjects withdrew their consent & 3 & 0 & 0 & 0 & 31 & 0 & 0 & 0 \\
\hline Subjects withdrew their consent (cluster) & 0 & 0 & 0 & 0 & 0 & 0 & 0 & 0 \\
\hline "Lost to follow-up" & 124 & 9 & 0 & 0 & 1533 & 0 & 9 & 52 \\
\hline "Lost to follow-up" (cluster) & 2 & 0 & 0 & 0 & 15 & 0 & 0 & 2 \\
\hline Main analysis of a total & 1578 & 378 & 181 & 36 & 21079 & 181 & 378 & 1180 \\
\hline Main analysis of a total (cluster) & 64 & 40 & 40 (several) & 18 & 372 & 24 & 40 & 54 \\
\hline Case "end point" wished to avoid & 326 & 135 & 8 (several) & 8 & 1912 & 44 & 135 & 250 \\
\hline Case "end point" wished to avoid (cluster) & 3 & 0 & 0 & 0 & 16 & 0 & 0 & 8 \\
\hline
\end{tabular}

Table 3: Most representative statistic for numeric variables. 


\section{VARIABLE NAME}

Was the study identified as a clinical trial in the title or subtitle?

Author nationality

Country where the study was performed

Is any earlier related systematic review quoted?

Is the "a priori" hypothesis explicitly detailed?

Are there references to an earlier publication of the same clinical trial?

Clinical trial type with reference to the number of participating centers

Are an epidemiologist and/or statistician involved as an author?

Is the collaboration of an epidemiologist and/or statistician indicated?

Type of funding

Random allocation system

Was a method of masked randomization followed?

Was the method of masked randomization used specified?

Does it mention if a hypothesis test ("p") was used in the baseline

comparison of groups?

Type of control

Type of clinical trial

If sequential, are the stopping rules written and what are they?

Is the clinical trial described as pragmatic?

Is the degree of masking assessment indicated?

Does it explain why the test is not blind?

Is the masking method indicated?

Does it indicate that the effectiveness of blinding was assessed?

Population type by age

Race of participant subjects indicated (cluster: also physicians) in the trial

Language of participant subjects indicated (cluster: also physicians)

Subject type

Does it mention whether the "alpha" error was taken into account in

obtaining the sample size?

Does it mention whether the "beta" error was taken into account in

obtaining the sample size?

Was the magnitude of minimum difference taken into account in

calculating the sample size?

Is a flowchart of patients shown?

Are there withdrawals due to side effects (in the flowchart or text)?

Treatment Type

Placebo used or no intervention, if standard treatment is effective?

If the answer is "1. Yes", why?

Has the use of placebo or no intervention made patients run additional risk of serious or irreversible damage?

Is the presence of permitted and/or prohibited concomitant therapies indicated?

Trial outcome

Were negative or inconclusive clinical trial results published?

Is the primary response variable explicitly indicated?

Assessment of outcome ("endpoint")

Was the clinical trial finalized sooner than scheduled?

Why the trial was stopped earlier than scheduled specified

Is "intention to treat analysis" carried out?

Are the values of "p" or "confidence intervals" (Cl) indicated?

Does it indicate whether a multivariate analysis was performed?

Is there an agency for data monitoring and safety such as the DSMB?

Are there serious adverse events in general?

Were there any amendments to the protocol during the course of the

trial?

If so, has the ethics committee been informed?

Is it specified whether the trial follows the CONSORT standards?

Is it mentioned whether an ethics committee has approved the clinical trial?

If so, is the appropriate ethics committee mentioned?

Have the potential subjects included in the study been informed of

different aspects of the clinical trial?
If the answer is yes, have they understood this information and has this been confirmed?

Does it mention if informed consent was obtained?

Was the informed consent obtained voluntary?

If "Yes" to question 95, is the type of consent specified, and is it witnessed and documented?

Does it indicate whether a parent/legal guardian in the case of minors or incompetent adults gave it?

If the IC was not obtained from legal representatives (not available), and the $\mathrm{CT}$ could not be delayed, was it obtained as soon as possible?

Has the disagreement of the potential subject, either a minor or incompetent, been respected, and IC conformity been given by his/her legal representative?

Do incompetent or minor subjects, who cannot give IC, participate as a necessary characteristic of the researched group?

Does it specify any information received by the patient at the time of obtaining informed consent?

Has the IC request been made under pressure or dependence?

Following the previous answer, was a properly qualified unrelated person designated in order to obtain consent?

Did any individual participant withdraw consent at any time during the investigation?

Were precautions taken on the confidentiality of personal information of subjects participating in the clinical trial?

Was informed consent to save and use the data obtained in the future given by subjects participating in clinical trials?

If the answer was "2. No," did a research ethics committee carry out the clinical trial after approval?

Are people injured by their participation in the study shown?

If they have been injured, have they been compensated for the harm they suffered?

If injury is caused to subjects participating, does the protocol cover the repair of such injury, so there are no side effects for any subject?

In the protocol, are arrangements outlined for the less beneficial interventions after finishing in order to equate all participants?

1.00

1.00

0.96

1.00

1.00

1.00

1.00

1.00

0.95

1.00

1.00

1.00

1.00

1.00

1.00

1.00

1.00

1.00

1.00

1.00

1.00

At the end, was the intervention identified as most beneficial provided for other participants who had not received it?

In accordance with the above answer, they were informed of this fact in the informed consent?

Have you informed all participating subjects of the overall results of the study?

Was any incentive offered to researchers, participating centers and/or subjects?

If so, specify the type and amount

If an incentive was offered, has it been provided and why so or not?

Is information given on whether there is a conflict of interest?

Type of information provided in relation to conflict of interest

1.00

1.00

1.00

1.00

1.00

1.00

1.00

1.00

1.00

Influence of the sponsor in writing, reviewing and/or publication of results 1.00 Is the clinical trial been registered?

Table 4: Variables with corresponding $\mathrm{k}$ value.

of Family Medicine" RCTs does explain those data less than conflict of interest.

Similar to our study, the most common source of funding in Lai et al. [31] was public (58.1\%), probably because CTs are very expensive. In this study, the significant adverse events were common (64.9\%), possibly by not studying safe medical interventions. Moreover the methodological quality is higher in our study, only appear in this review in $45.9 \%$ the primary endpoint, and sample size calculation in $39.2 \%$, masked randomization in $29.7 \%$, blind in $12.2 \%$, and "intentionto-treat" in $27 \%$. Ifeacho et al. [32] observed lower rates than ours in relation to the appearance of CT in the title (40\%), description of the design (12\%), sample size (20\%) and random assignment (32\%). Moreover their study obtained less frequent results regarding the type of masking (24\%), funding-sponsors (28\%) and statistical methods (22\%). Poolman et al. [33] found fewer cases of an epidemiologist as 
author (9\%), multicenter types and following of CONSORT (13\%) standards than in our study. We believe it might be because the journals assessed in these studies did not follow CONSORT standards completely.

Anttila et al. [34] performed after CONSORT, obtained similar results to ours on justification, objectives and design.

In 2011 Kiehna et al. [35] found data with rates lower than our study in the justification and design, in contrast with the description of significant adverse events. The sequence of randomization (41\%), the analyses of "intention-to-treat" (33\%) and masking (19\%) were also significantly lower than those included in our review. Augestad et al. [36] observed less frequency of CT registration (25\%), funding (95\%), performing in PC (70\%) and masking type (15.6\%). The mean Jadad score was 2, also below our findings. This is perhaps because they assessed more pharmacological studies with questionable quality.

Coinciding with Baskerville et al. [11] we only have access to the published CT and not the original data (that may differ). There is variability between the studies regarding the measurement of the "endpoints", due to the many types of variables found by the study treatment.

Would be desirable a study based on an analysis of disciplines, specialties or a particular subject in the future.

The authors recommend that a greater emphasis on proper implementation of the CONSORT standards, could take an improvement in quality of Family Medicine clinical trials published.

Therefore, a deeper insight into obtain a better methodological and ethical quality, it will lead us to further analysis in the evaluation of a new medical treatment before use with patients. In this way, it could avoid many of the side effects or ineffectiveness of new therapies, so that when they were cast safe and effective into the public. This also would be a great saving for the health system costs and potential demands of patients in the future.

\section{Conclusions}

We observe that the most frequent CT published in Annals of Family Medicine (2010-2013) are: multicenter $>5$, with public funding, cluster controlled open parallel, with decentralized masked randomization using an active treatment as a control, in a 6-12 months period; made up of in a biracial patient group and applying a method of medical intervention with positive results in $50 \%$ (measured by questionnaire). In $50 \%$ the intention-to-treat analyses are performed, and they show serious adverse events and good quality (Jadad 3). Furthermore, IC (verbal or not mentioned), no incentive and no conflicts of interest occur more frequently than in other publications cited. Lastly, we find optimal $\kappa$.

Following the CONSORT standards publication, it has increased the overall quality of the CTs published. But there are some areas for improvement in the methodological and ethical quality of the CTs published from 2010 to 2013 in Annals of Family Medicine.

\section{Acknowledgments}

This study would not have been possible without the support offered by a future member of my family throughout the investigation process.

\section{Conflict of Interest}

Author Alberto Castaño-García declares that he has no conflict of interest. Author Francisco Guillén-Grima declares that he has no conflict of interest. Author Pilar León-Sanz declares that she has no conflict of interest.

\section{References}

1. Guyatt GH, Oxman AD, Vist GE, Kunz R, Falck-Ytter Y, et al. (2008) GRADE: an emerging consensus on rating quality of evidence and strength of recommendations. BMJ 336: 924-926.

2. Pildal J, Chan AW, Hróbjartsson A, Forfang E, Altman DG, et al. (2005) Comparison of descriptions of allocation concealment in trial protocols and the published reports: cohort study. BMJ 330: 1049.

3. Moher D, Hopewell S, Schulz KF, Victor MontoriPeter C, Gotzsche, et al (2010) CONSORT 2010 explanation and elaboration: updated guidelines for reporting parallel group randomized trials. BMJ 340: c869.

4. Dechartres A, Charles P, Hopewell S, Ravaud P, Altman DG (2011) Reviews assessing the quality or the reporting of randomized controlled trials are increasing over time but raised questions about how quality is assessed. J Clin Epidemiol 64: 136-144.

5. Katrak P, Bialocerkowski AE, Massy-Westropp N, Kumar S, Grimmer KA (2004) A systematic review of the content of critical appraisal tools. BMC Med Res Methodol 4: 22.

6. http://www.consort-statement.org/about-consort/endorsers

7. Mills EJ, Wu P, Gagnier J, Devereaux PJ (2005) The quality of randomized tria reporting in leading medical journals since the revised CONSORT statement. Contemp Clin Trials 26: 480-487.

8. Hooft L, Korevaar DA, Molenaar N, Bossuyt PM, Scholten RJ (2014) Endorsement of ICMJE's Clinical Trial Registration Policy: a survey among journal editors. Neth J Med 72: 349-355.

9. Moher D, Liberati A, Tetzlaff J, Altman DG, The PRISMA Group (2009) Preferred Reporting Items for Systematic Reviews and Meta-Analyses: The PRISMA Statement. PLoS Med 6: e1000097

10. Baskerville NB, Liddy C, Hogg W (2012) Systematic review and meta-analysis of practice facilitation within primary care settings. Ann Fam Med 10: 63-74.

11. Péron J, Pond GR, Gan HK, Chen EX, Almufti R, et al. (2012) Quality of reporting of modern randomized controlled trials in medical oncology: a systematic review. J Natl Cancer Inst 104: 982-989.

12. Ndebele P (2013) The Declaration of Helsinki, 50 years later. JAMA 310: 21452146

13. Millum J, Wendler D, Emanuel EJ (2013) The 50th anniversary of the Declaration of Helsinki: progress but many remaining challenges. JAMA 310 2143-2144.

14. Schulz KF, Altman DG, Moher D, for the CONSORT Group (2010) CONSORT 2010 Statement: updated guidelines for reporting parallel group randomised trials. BMJ 340: c332

15. Bai Y, Gao J, Zou DW, Li ZS (2009) Methodological reporting of randomized clinical trials in major gastroenterology and hepatology journals in 2006 Hepatology 49: 2108-2112.

16. Castaño García A, Maria Jose R, Carlos Alverez D, Nolasco A, Mancho J, et al (1999) Evolución de la calidad de los ensayos clínicos publicados en 4 revistas generales de medicina (1993-5 y 2004). Rev Esp Salud Pública 73: 445-453.

17. Moher D, Schulz KF, Altman D, CONSORT Group (Consolidated Standards of Reporting Trials) (2001) The CONSORT statement: revised recommendations for improving the quality of reports of parallel-group randomized trials. JAMA 285: 1987-1991.

18. http://www.wma.net/es/30publications/10policies/b3/

19. Thorpe KE, Zwarenstein M, Oxman AD, Treweek S, Furberg CD, et al. (2009) A pragmatic-explanatory continuum indicator summary (PRECIS): a tool to help trial designers. CMAJ 180: E47-57.

20. Gartlehner G, Hansen RA, Nissman D, Lohr KN, Carey TS (2006) Criteria for Distinguishing Effectiveness From Efficacy Trials in Systematic Reviews.

21. Grant AM, Altman DG, Babiker AB, Campbell MK, Clemens FJ, et al. (2005) Issues in data monitoring and interim analysis of trials. Health Technol Assess 9: 1-238, iii-iv.

22. https://www.mccallum-layton.co.uk/tools/statistic-calculators/confidenceinterval-for-mean-calculator/\#confidence-interval-for-mean-calculator

23. Licciardone JC, Minotti DE, Gatchel RJ, Kearns CM, Singh KP (2013) Osteopathic manual treatment and ultrasound therapy for chronic low back pain: a randomized controlled trial. Ann Fam Med 11: 122-129. 
Citation: Garcia C, Grima G, Sanz L (2016) Methodological and Ethical Quality Checklist Assessment in Issues of Annals of Family Medicine Clinical Trials (2010-2013). Fam Med Med Sci Res 5: 200. doi:10.4172/2327-4972.1000200

24. Yank V1, Rennie D (2002) Reporting of informed consent and ethics committee approval in clinical trials. JAMA 287: 2835-2838.

25. Cook DJ, Sackett DL, Spitzer WO (1995) Methodologic guidelines for systematic reviews of randomized control trials in health care from the Potsdam Consultation on Meta-Analysis. J Clin Epidemiol 48: 167-171.

26. Sinha S, Sinha S, Ashby E, Jayaram R, Grocott MP (2009) Quality of reporting in randomized trials published in high-quality surgical journals. J Am Coll Surg 209: 565-571.

27. Agha RA, Camm CF, Doganay E, Edison E, Siddiqui MR, et al. (2014) Randomised controlled trials in plastic surgery: a systematic review of reporting quality. Eur J Plast Surg 37: 55-62.

28. O'Meara S, Riemsma R, Shirran L, Mather L, ter Riet G (2001) A rapid and systematic review of the clinical effectiveness and cost-effectiveness of orlistat in the management of obesity. Health Technol Assess 5: 1-81.

29. Laframboise MA, Degraauw C (2011) The effects of aerobic physical activity on adiposity in school-aged children and youth: a systematic review of randomized controlled trials. J Can Chiropr Assoc 55: 256-268.

30. Panic N, Leoncini E, de Belvis G, Ricciardi W, Boccia S (2013) Evaluation of the endorsement of the preferred reporting items for systematic reviews and meta-analysis (PRISMA) statement on the quality of published systematic review and meta-analyses. PLoS One 8: e83138.

31. Lai R, Chu R, Fraumeni M, Thabane L (2006) Quality of randomized controlled trials reporting in the primary treatment of brain tumors. J Clin Oncol 24: 11361144

32. Ifeacho S, Ajayi O, Hannan SA (2011) Are randomised controlled trials involving adenotonsillectomy well reported? Int J Pediatr Otorhinolaryngol 75: 939-942.

33. Poolman RW, Struijs PA, Krips R, Sierevelt IN, Lutz KH, et al. (2006) Does a "Level I Evidence" rating imply high quality of reporting in orthopaedic randomised controlled trials? BMC Med Res Methodol 6: 44.

34. Anttila H, Malmivaara A, Kunz R, Autti-Rämö I, Mäkelä M (2006) Quality of reporting of randomized, controlled trials in cerebral palsy. Pediatrics 117 2222-2230.

35. Kiehna EN, Starke RM, Pouratian N, Dumont AS (2011) Standards for reporting randomized controlled trials in neurosurgery. J Neurosurg 114: 280-285.

36. Augestad KM, Berntsen G, Lassen K, Bellika JG, Wootton R, et al. (2012) Standards for reporting randomized controlled trials in medical informatics: a systematic review of CONSORT adherence in RCTs on clinical decision support. J Am Med Inform Assoc 19: 13-21.
Citation: Garcia C, Grima G, Sanz L (2016) Methodological and Ethical Quality Checklist Assessment in Issues of Annals of Family Medicine Clinical Trials (2010-2013). Fam Med Med Sci Res 5: 200. doi:10.4172/2327-4972.1000200
OMICS International: Publication Benefits \& Features

Unique features:

Increased global visibility of articles through worldwide distribution and indexing Showcasing recent research output in a timely and updated manner

Special issues on the current trends of scientific research

Special features:

- 700 Open Access Journals

50,000 Editorial team

Copid review process

Quality and quick editorial, review and publication processing

Indexing at PubMed (partial), Scopus, EBSCO, Index Copernicus, Google Scholar etc.

Sharing Option: Social Networking Enabled

Authors, Reviewers and Editors rewarded with online Scientific Credits

Better discount for your subsequent articles

Submit your manuscript at: http://www.omicsonline.org/submission/ 